\title{
Aneurysm of the tibial-saphenous fistula in hemodialysis patient: the results of surgical treatment
}

This article was published in the following Dove Press journal:

Vascular Health and Risk Management

3I October 20 I I

Number of times this article has been viewed

\section{Murat Günday}

Thoracic and Cardiovascular Surgery Training and Research Hospital, Cardiovascular Surgery Department, Trabzon, Turkey
Correspondence: Murat Günday Bașkent University, Department of Cardiovascular Surgery, Konya, Turkey, 42100

Tel +9005065957302

Fax +90332 2570637

Email gundaymurat@yahoo.com
Abstract: Arteriovenous fistulas are widely used for hemodialysis patients with end-stage renal failure. Due to the lack of suitable veins because of the arteriovenous fistulas previously opened in the upper extremity, alternative access routes are being tested. Few complications of long-term alternative arteriovenous fistulas have been reported in the literature. We report the results of surgical repairs of aneurysms that occurred on anterior tibial-saphenous arteriovenous fistulas (along the vein) in patients with end-stage renal disease after 5 years on hemodialysis.

Keywords: vascular access, aneurysm, saphena magna, renal failure, long term

\section{Introduction}

Generally, arteriovenous (A-V) fistulas are performed in the veins of the upper extremity and in the non-dominant arm. Brescia-Cimino fistulas are the gold standard as an access route during hemodialysis. ${ }^{1}$ In patients that undergo dialysis repetitively, the fistula located in the wrist becomes obstructed over time and the patient cannot undergo dialysis from this same point. In such situations, it is preferred to form a new fistula or to use polytetrafluoroethylene (PTFE) graft. ${ }^{2}$ Another method is to form alternative access routes. ${ }^{3}$ For $\mathrm{A}-\mathrm{V}$ fistulas, the most common complication is aneurysmal degeneration, which is seen in the late stage, and which appears like a true or false aneurysm. In this study, we report an A-V fistula aneurysm that was developed as an alternative to an A-V fistula between the anterior tibial artery and saphenous vein, a site not commonly reported in the literature, also the surgical treatment that we performed.

\section{Case report}

The 35-year-old female patient had previously repeatedly had A-V fistulas constructed on both upper extremities. Double-lumen catheters had been placed repeatedly in subclavian veins on both sides prior to the construction of A-V fistulas in her upper extremity. Allografts had been taken out from upper extremities because of graft infection. Bilaterally axillar veins were occluded. As there were no eligible veins to form a fistula in the upper extremity, surgery had been performed 5 years ago on the right lower extremity, between the anterior tibial artery and saphenous vein.

The patient presented to our out-patient department complaining of ballooning on the saphenous vein for about a year and especially a foot pain that had recently started to appear after walking. The patient's physical systemic examinations were normal. A strong thrill could be obtained on the aneurysm (Figure 1). The pulse on the anterior tibial artery showed a weakening compared with the other foot. Preoperative 


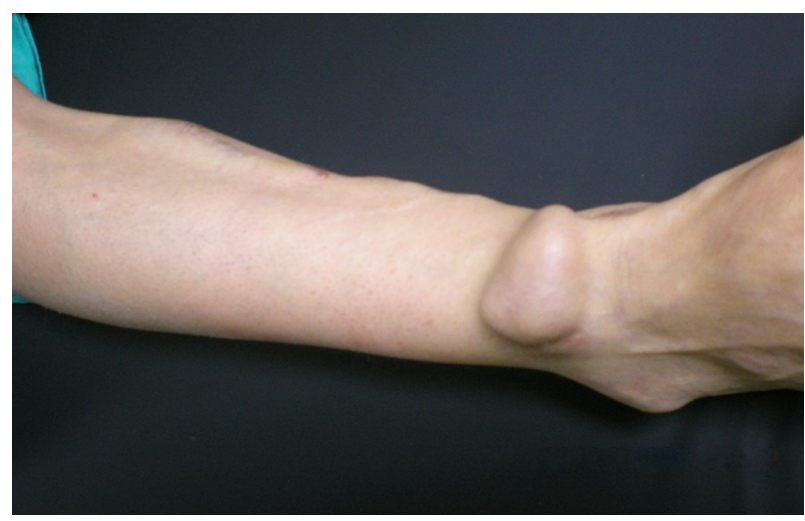

Figure I The aneurysm on saphenous vein.

laboratory findings showed no pathologic evidence, except a lowered hematocrit value. Blood pressure $(120 / 80 \mathrm{mmHg})$ was normal. The patient underwent a venous Doppler ultrasonography (USG) of the lower extremity in the radiology department. The aneurysm $(45 \times 30 \mathrm{~mm})$ was detected in Doppler USG (Figure 2). The patient was taken into the operating room. A tourniquet was put on at the popliteal level. After administering local anesthetic, the aneurysm was opened on the vesicle. Subcutaneous tissue was gently dissected and bleeding was controlled from the proximal and distal aneurysm sides (Figure 3). The patient was given $5000 \mathrm{U}$ heparin. After ensuring the resolution of thrill on the vesicle by tightening the tourniquet at $200 \mathrm{mmHg}$, venotomy was performed. The anastomotic region was narrowed with a purse suture using 4-0 prolene (Figure 4). Approximately $0.5-2 \mathrm{~cm}$ was cut from each side of the opened vein. The anastomosis vesicle was sutured over and over with 4-0 prolene (Figure 5). The diameter was reduced to approximately $0.5-1 \mathrm{~cm}$. A strong thrill was palpated on the aneurysm. The patient was discharged on the same

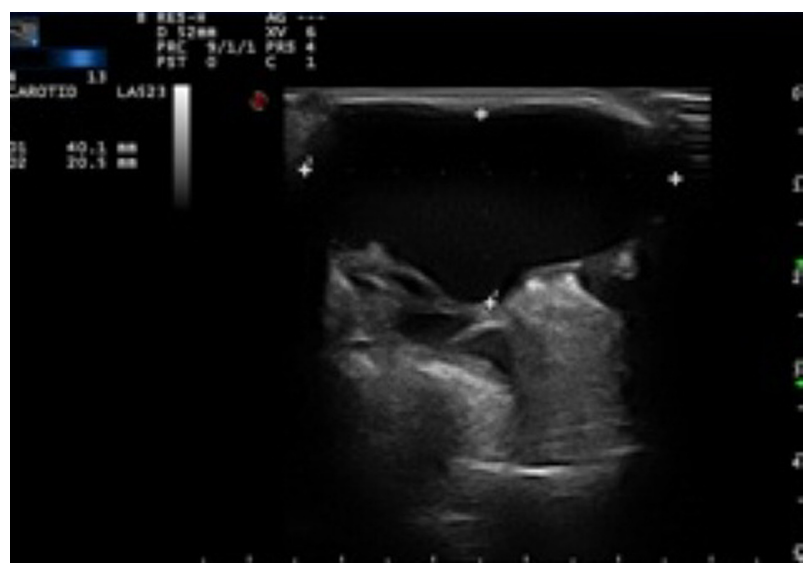

Figure 2 The aneurysm is seen in Doppler ultrasonography.

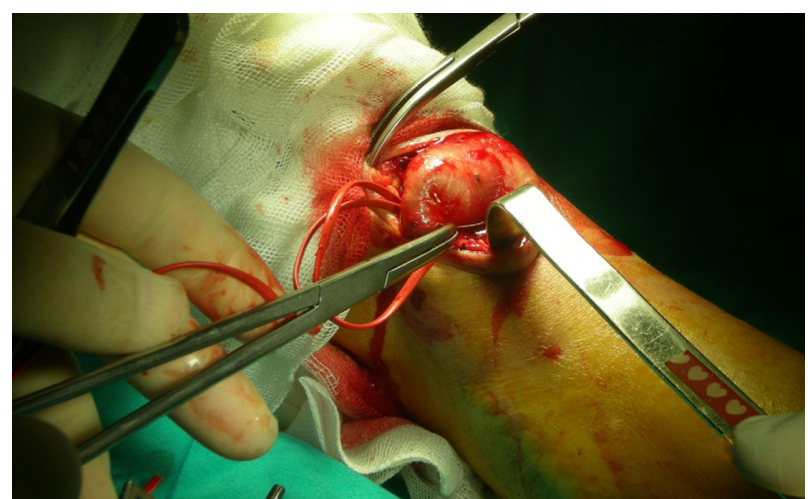

Figure 3 The bleeding was controlled from the proximal and distal aneurysm sides.

day and underwent dialysis from the same vein 2 days later. Low-molecule-weight heparin was used during the first dialysis after the surgical repair of the aneurysm. During follow-ups in the outpatient department, aspirin was given. It was observed that the patient's complaints about foot pain on walking had lessened.

\section{Discussion}

The types of alternative A-V fistulas include saphenofemoral and saphenopopliteal loop fistulas, transposition of femoral vein to popliteal artery, axillary artery-popliteal vein PTFE bypass, ${ }^{4}$ posterior tibial artery-saphenous vein fistula, ${ }^{5}$ and femoro-femoral loop fistula.

Pierre-Paul et $\mathrm{al}^{3}$ did a sapheno-femoral loop graft on seven patients. Perioperative acute occlusion or steal syndrome was not observed. Mean duration of primary patency was found to be 7 months. In the hemodialysis, $71.4 \%$ of the aneurysm fistulas (5/7) were functional. Six patients showed mild or moderate leg edema that required the use of compression socks. In another study, a tibial post-saphenous vein fistula was formed on 3 patients, who were followed-up over 12 months. ${ }^{5}$

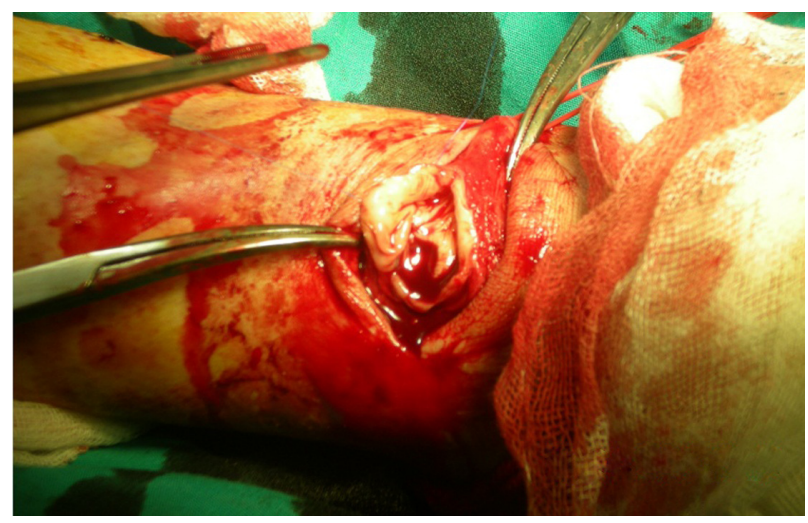

Figure 4 The anastomotic region was narrowed with a purse suture using 4-0 prolene. 


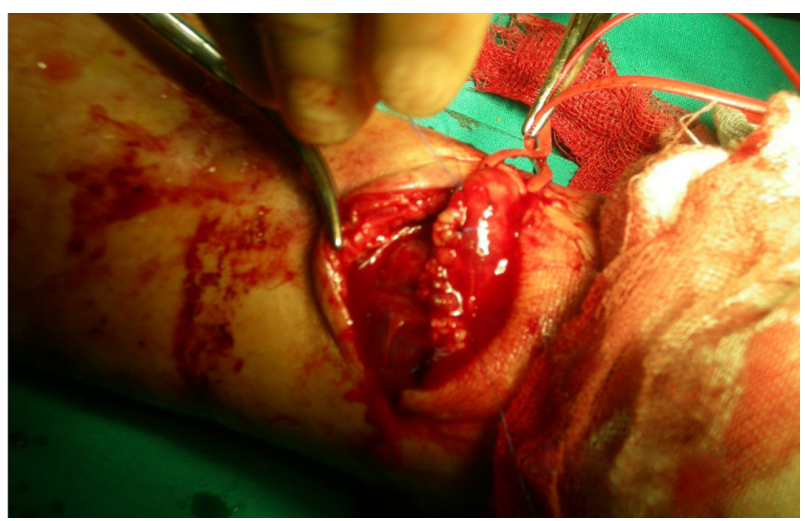

Figure 5 Anastomosis vesicle was sutured over and over with 4-0 prolene.

While one patient developed thrombosis at month 4, dialysis was successful in the other two patients. Our patient underwent dialysis without problems for 5 years via an A-V fistula that we formed between the tibial anterior and saphenous vein, a procedure that is reported for the first time.

Fistula aneurysm is observed as a result of collagen matrix degeneration occurring on the vein wall. Generally, repeated punctures of an A-V fistula on the same site accelerate the development of an aneurysm. The potential severity of the aneurysm is high due to the risk of rupture and possibly fatal hemorrhage. Doppler USG is the gold standard in the diagnosis of A-V fistula aneurysms and in postoperative follow-up. ${ }^{6}$ We did Doppler USG to evaluate the aneurysm before the operation.

For the treatment of the aneurysmal complications of arteriovenous fistulas, ligations, compression together with USG, endovascular graft implantation, or the injection of thrombin are performed. ${ }^{7-9}$ However, surgical repair is still the gold standard. In surgical treatment, ligation or the narrowing of the aneurysm vesicle can be performed.

Lo and $\operatorname{Tan}^{10}$ reported 15 cases of uncomplicated aneurysmal dilatation of AV fistulas over a 3-year period. All underwent plication of the aneurysm. Most patients were discharged after 1 or 2 days. Only one case of postoperative complication was reported, in a patient who had superficial wound bleeding, which was stopped by adrenaline packing. Although the risk of bleeding is lower in the ligation, the fact that the fistula of the patient cannot be used a second time is a disadvantage. Moreover, for dialysis, the patient should have a double-lumen catheter. There are many complications of catheterization. ${ }^{10}$ In our patient, dialysis was carried out on the same $\mathrm{A}-\mathrm{V}$ fistula 2 days after the plication procedure for a routine dialysis program.

Berard et al noted that reinforced venous aneurysmorrhaphy is effective in controlling venous dilation and achieving patency. ${ }^{11}$ Also, Balaz et al found that to offset the weakening of the venous wall by suture following aneurysmorrhaphy, an external polyethylene terephthalate prosthesis needed to be implanted in the vein to prevent the development of intimal hyperplasia in the de novo created AV fistula. ${ }^{12} \mathrm{We}$ did not use the external PTFE graft to protect wall weakening, because it is a foreign body that can be infected after repeated puncture, and because the vessel wall is thickened and not fragile during the operation. We have performed plication of the aneurysm in 15 patients. After surgery, the patients were observed for 39 months on average (range, 7-56 months). The patients did not suffer from any complications, including rupture and thrombosis. ${ }^{13}$

Reported use of this type of fistula, in which anterior tibial artery and saphenous veins are used, is limited. However, it can be considered as an alternative approach in difficult cases. A-V fistula aneurysm is also seen on the saphenous vein, which is the alternative A-V fistula site. If a surgical intervention is planned for the treatment, the plication of the aneurysm vesicle should be preferred to ligation because vein access is limited.

\section{Disclosure}

The author reports no conflicts of interest in this work.

\section{References}

1. Gelabert HA, Freischlag JA. Hemodialysis access. In: Rutherford RB, editor. Vascular Surgery. 5th ed. Philadelphia, PA: W.B. Saunders; 2000:1466-1477.

2. Hakim R, Himmelfarb J. Haemodialysis access failure: a call to action. Kidney Int. 1998;54(4):1029-1040.

3. Pierre-Paul D, Williams S, Lee T, Gahtan V. Saphenous vein loop to femoral artery arteriovenous fistula: a practical alternative. Ann Vasc Surg. 2004;18(2):223-227. [Abstract.]

4. Chemia ES, Korrakuti L, Makanjuola D, Chang RW. Vascular Access in hemodialysis patients with central venous obstruction or stenosis: one center's experience. Ann Vasc Surg. 2005;19(5):692-698.

5. Flora HS, Chaloner EJ, Day C, Barker SG. The ankle arterio-venous fistula: an approach to gaining vascular access for renal haemodialysis. Eur J Vasc Endovasc Surg. 2001;22(4):376-378.

6. Eugster T, Wigger P, Bölter S, Bock A, Hodel K, Stierli P. Brachial artery dilatation after arteriovenous fistulae in patients after renal transplantation: a 10- year follow-up with ultrasound scan. JVasc Surg. 2003;37(3):564-567.

7. Gray RJ, Stone WM, Fowl RJ, Cherry KJ, Bower TC. Management of true aneurysms distal to the axillary artery. J Vasc Surg. 1998;28(4): 606-610.

8. Lin PH, Johnson CK, Pullium JK, Koffron AJ, Conklin B, Terramani TT, et al. Transluminal stent graft repair with Wallgraft endoprosthesis in a porcine arteriovenous graft pseudoaneurysm model. J Vasc Surg. 2003;37(1):175-181.

9. Clark TW, Abraham RJ. Thrombin injection for treatment of brachial artery pseudoaneurysm at the site of a hemodialysis fistula: report of two patients. Cardiovasc Intervent Radiol. 2000;23(5):396-400.

10. Lo HY, Tan SG. Arteriovenous fistula aneurysm-plicate, not ligate. Ann Acad Med Singapore. 2007;36(10):851-853. 
11. Berard X, Brizzi V, Mayeux S, et al. Salvage treatment for venous aneurysm complicating vascular access arteriovenous fistula: use of an exoprosthesis to reinforce the vein after aneurysmorrhaphy. Eur J Vasc Endovasc Surg. 2010;40(1):100-106.

12. Balaz P, Rokosny S, Klein D, Adamec M. Aneurysmorrhaphy is an easy technique for arteriovenous fistula salvage. $J$ Vasc Access. 2008;9(2):81-84. [Abstract.]
13. Ökten CC, Günday M, Demirbaş M. Surgical treatment of venous aneurysms developing in arteriovenous fistulae in hemodialysis patients. Turkish J Thorac Cardiovasc Surg. 2010;18(3):196-199.

\section{Publish your work in this journal}

Vascular Health and Risk Management is an international, peerreviewed journal of therapeutics and risk management, focusing on concise rapid reporting of clinical studies on the processes involved in the maintenance of vascular health; the monitoring, prevention and treatment of vascular disease and its sequelae; and the involvement of metabolic disorders, particularly diabetes. This journal is indexed on PubMed Central and MedLine. The manuscript management system is completely online and includes a very quick and fair peer-review system, which is all easy to use. Visit http://www.dovepress.com/ testimonials.php to read real quotes from published authors.

Submit your manuscript here: http://www.dovepress.com/vascular-health-and-risk-management-journal 